\title{
Desplazamientos del modernismo: Greenberg en el pensamiento artístico de José Luis Castillejo
}

\section{Displacements of modernism: Greenberg in the artistic thinking of José Luis Castillejo}

\author{
Luis Cáceres Cantero \\ Universidad Antonio de Nebrija
}

Fecha de recepción: 23 de abril de 2018

Fecha de aceptación: 25 de marzo de 2019

Anuario del Departamento de Historia y Teoría del Arte

Vol. 31, 2019, pp. 57-74

ISSN: 1130-5517, eISSN: 2530-3562

https://doi.org/10.15366/anuario2019.31.003

\section{RESUMEN}

Este trabajo reflexiona sobre el debate formalista del modernismo greenberguiano al que se adhiere el escritor, diplomático y coleccionista José Luis Castillejo en su trabajo, tras su expulsión del grupo Zaj a finales de los 60, para analizarlo críticamente y examinar su validez en la práctica del escritor. El punto de partida del texto es un estudio más detallado de la correspondencia hallada en archivos públicos de España y Estados Unidos entre el escritor y el crítico Clement Greenberg desarrollada entre 1981 y 1983, un material al que no se le ha prestado la atención que se merece por su relevancia para la historiografía nacional e internacional.

\section{PALABRAS CLAVE}

Crítica de arte formalista. Escritura experimental. Castillejo. Greenberg.

\begin{abstract}
This work reflects on the formalist debate of Greenbergian modernism acquired by the writer, diplomat and collector José Luis Castillejo in his work, after his stage in the Zaj group at the end of the 60 s, to analyze it critically and examine its validity in the practice of the writer. The starting point of the text is the discovery of an unpublished correspondence found in public archives of Spain and the United States between the writer and the critic Clement Greenberg maintained between 1981 and 1983, a material that has not been given the attention it deserves due to its relevance to national and international historiography.
\end{abstract}

\section{KEY WORDS}

Formalist critique. Experimental writing. Castillejo. Greenberg. 


\section{Introducción}

El 26 de julio de 1978 el escritor, diplomático y coleccionista José Luis Castillejo era designado Embajador en Nigeria ${ }^{1}$. Castillejo, que mantuvo su residencia en la ciudad costera de Lagos hasta 1986, ocupó también el cargo de Embajador de la vecina República popular de Benín durante esos años. Era el último período de una carrera diplomática que había comenzado en 1955, y que le había llevado a ocupar diferentes cargos en las embajadas de Washington, Argel, Bonn, Stuttgart, Estrasburgo o Houston.

Todos esos viajes, experiencias y conocimientos adquiridos fueron determinantes para el desarrollo de uno de los conjuntos de escritura experimental más originales de nuestro país. La figura de Castillejo se distingue por desarrollar un proceso de análisis en torno a la escritura que le llevó a confeccionar más de 40 obras, entre las que se encuentran numerosos libros, cartones y ejercicios de escritura abierta ${ }^{2}$, algunos de los cuales aún hoy continúan estando inéditos. El ejercicio de experimentación en torno al medio específico de la escritura es lo que distingue la obra de Castillejo. Esta se sitúa en paralelo a la operada en la pintura abstracta dentro de los parámetros del modernismo, según fueron desarrollados por Clement Greenberg, cuyo contacto con Castillejo ocupa parte de este texto.

Entre 1981 y 1983, Castillejo mantuvo una comunicación personal e intelectual con el crítico norteamericano Clement Greenberg, impulsor fundamental del modernism, cuyas ideas ya en aquella época eran ampliamente cuestionadas, dejando de ser hegemónicas ${ }^{3}$. En junio de 1981 comenzó una relación entre ambos bien documentada, a través de una correspondencia accesible a través de los archivos del Museo Nacional Centro de Arte Reina Sofía en Madrid y los Archives of American Art. Smithsonian Institution en Washington D.C. ${ }^{4}$, que aporta detalles reveladores acerca de la escritura post-zaj del diplomático y que nos habla de un contexto artístico basado en la relación entre Estados Unidos y Francia. Castillejo ya compartía con Greenberg, antes de conocerse personalmente, la manera de entender la práctica artística dentro de los cánones del modernism. Conceptos tan sustanciales para el modernism de Greenberg como el de "medium-specificity" (Greenberg usaba este término para referirse al área de competencia única y propia de cada forma artística, mientras que Castillejo usaba recurrentemente el concepto de especificidad diferencial), la ausencia de narratividad, pureza o la divergencia con respecto al nihilismo de la neo-vanguardia, son referencias básicas en la escritura de Castillejo desde finales de 1969, cuando se desvinculó por completo del colectivo comandado por Juan Hidalgo ${ }^{5}$. Es en ese momento y en solitario que Castillejo se enfrasca en un camino de experimentación en torno a la escritura, por otro lado, deudora de Zaj.

\footnotetext{
1 Castillejo estuvo destinado en Nigeria desde julio de 1978 hasta mayo de 1986. Esta información ha sido obtenida a partir de la consulta en el Ministerio de Asuntos Exteriores de Madrid de la carrera diplomática de José Luis Castillejo. Sus lugares de residencia como diplomático, así como sus viajes constantes por Europa y Estados Unidos, van a estar conectados con su trayectoria como escritor y coleccionista. Castillejo se consideraba a sí mismo escritor; véase José Luis CASTILLEJO, Ensayos sobre Arte y Escritura, Madrid, Ediciones La Bahía, 2013, p. 115.

2 El término de "ejercicio de escritura abierta" viene recogido en José Luis Castillejo y la Escritura Moderna (Comis. Henar Rivière y Manuel Olveira), León, MUSAC y Centro Andaluz de Arte Contemporáneo (catálogo de exposición celebrada del 17 de febrero al 27 de mayo), 2018, pp. 289-459.

3 Para una revisión crítica del modernismo de Greenberg, véase Francis Fascina (ed.), Pollock and After: the critical debate, Londres y Nueva York, Psychology Press, 2000.

${ }^{4}$ La correspondencia de Greenberg a Castillejo se puede consultar en los fondos de la biblioteca del Museo Reina Sofía. Se trata de 13 documentos con Número de Registros del 144202 al 144214. En cuanto a la correspondencia de Castillejo a Greenberg, ésta se puede consultar en los fondos de los Archives of American Art. Smithsonian Institution de Washington D.C. con referencia: Series 3. Correspondence, 1937-1983. Folder 23, Castillejo, Jose Luis 1981-1983. Clement Greenberg papers, $1937-1983$.

5 Javier Maderuelo, Escritura Experimental en España, Catálogo de exposición. Madrid, Círculo de Bellas Artes, 2014-15, pp. 76-78.
} 


\section{Primeros contactos con los Estados Unidos}

La trayectoria formativa de Castillejo, que provenía de una familia aristocrática cordobesa ${ }^{6}$, estuvo marcada por un interés sostenido por el arte y la cultura, con especial predilección por la filosofía ${ }^{7}$. Castillejo, tras estudiar la carrera de Derecho entre Sevilla y Madrid, donde se licenció en 1951, había sido alumno de Tierno Galván durante sus años de formación en la escuela diplomática entre 1953 y 1959 ${ }^{8}$, asistiendo a numerosas clases, charlas o conferencias en estancias breves en universidades como Cambridge, Oxford, Heidelberg, Friburgo o Poitiers de filósofos como Bertrand Russell, Heidegger o Karl Popper; Castillejo también tenía a Wittgenstein y sus reflexiones sobre el lenguaje como referente para su genealogía conceptual. El año de su ingreso en la escuela diplomática coincidía con el de los llamados Pactos de Madrid entre Estados Unidos y la dictadura franquista, por los que se instalarían bases militares norteamericanas en España a cambio de ayuda económica y militar. Ese mismo año, tras la celebración en 1951, en Madrid, de la I Bienal Hispanoamericana se celebró el I Congreso Internacional de Arte Abstracto como cierre de un proceso de cierta reapertura a un arte moderno que había sido cercenado por la guerra civil. Una transformación que en realidad se había iniciado en los años cuarenta con la eclosión de colectivos como el Grupo Pórtico, Dau al Set o la Escuela de Altamira.

Coincidiendo con la etapa de aperturismo del régimen franquista y la llegada de Fernando Castiella como Ministro de Asuntos Exteriores ${ }^{9}$, en 1959, Castillejo fue enviado a la Embajada de Washington como Secretario de Tercera Clase. De esta manera el escritor entró en contacto con un mundo artístico marcado por el auge de los creadores del expresionismo abstracto o el informalismo francés o español. En Washington, sus visitas a la Phillips Gallery fueron constantes, y los viajes a Nueva York empezaron también a convertirse en una práctica habitual ${ }^{10}$. Fue a través del coleccionismo, que Castillejo tomó un contacto cada vez más profundo y directo con el arte.

Las obras adquiridas por el escritor a lo largo de su trayectoria como diplomático fueron numerosas. En una de las cartas a Greenberg, concretamente en la del 2 de enero de 1981, Castillejo enumera las obras de arte que poseía en aquellos momentos. Se trata de una gran colección de pintura de artistas que él separa por epígrafes entre modernistas americanos, pintores franceses u obras pintadas en Francia por autores extranjeros (fundamentalmente obras de los Supports/Surfaces franceses), pintores ingleses, pintores españoles (Antoni Tàpies, José Guerrero, Juan Genovés, Miguel Angel Campano o Carlos León), autores alemanes, y un epígrafe de "otros" en el que destacan dos dibujos de Giacometti. Se debe reseñar también que Castillejo por estas fechas poseía 26 pinturas y gran cantidad de dibujos del integrante de Supports/Surfaces Louis Cane, un artista predilecto para el escritor. Esta colección la empezó a atesorar desde su aterrizaje en Estados Unidos como diplomático de un régimen que, no podemos olvidar, era dictatorial y de corte fascista.

\footnotetext{
6 Acerca de los orígenes familiares de Castillejo, véase: José Luis Castillejo y la Escritura Moderna (Comis. Henar Riviere y Manuel Olveira), León, MUSAC y Centro Andaluz de Arte Contemporáneo (catálogo de exposición celebrada del 17 de febrero al 27 de mayo), 2018, pp. 11-18.

7 En 1968 Castillejo publica Actualidad y Participación, que recoge escritos de crítica artística realizados desde 1966. Se trata de un "libro didáctico y expositivo" que destacaba la importancia de la participación en los debates en torno a las artes y las letras. José Luis FernáNDEZ de CASTILlejo, Actualidad y participación. Una filosofía contemporánea, Madrid, Tecnos, 1968.

8 Enrique Tierno Galván, durante los años de formación de Castillejo en la Escuela Diplomática, era catedrático de Derecho Político en la Universidad de Salamanca. Esta actividad la combinaba con la formación de los alumnos de la Escuela Diplomática en Madrid.

9 María Dolores Jiménez-Blanco, Arte y Estado en la España del siglo XX, Madrid, Alianza, 1989, p. 14.

10 En una entrevista mantenida el 5 de diciembre de 2017 con el pintor Carlos León, amigo íntimo de Castillejo desde finales de los 60, éste me comenta "cómo Castillejo construyó un gusto enormemente condicionado por su primer destino como diplomático que fue Washington. Allí vio la obra de los pintores del Expresionismo Abstracto de la Segunda Generación como Kenneth Noland, Morris Louis o Helen Frankenthaler, y estuvo en menor contacto con el espacio artístico de Nueva York".
} 
Durante aquella época, en uno de sus viajes a Nueva York, Castillejo entró en contacto con Manuel Barbadillo, José Guerrero y Esteban Vicente, todos ellos aún poco conocidos en España ${ }^{11}$. A través de Barbadillo y su fe puesta en el éxito a nivel internacional de la pintura española, el escritor se decidió a adquirir obra de Antoni Tàpies ${ }^{12}$. La galería Martha Jackson de Nueva York, inaugurada en 1952 y clausurada en 1969, fue una de las primeras salas que apostó por jóvenes promesas del nuevo arte europeo. Tàpies fue uno de esos artistas apoyados por Jackson al que la sala le dedicó su primera exposición individual en la ciudad de los rascacielos. Hasta esa sala se dirigió Castillejo para adquirir varias obras de Tàpies, entre las cuales estaban Argile y Seis Manchas Negras ${ }^{13}$.

El crítico norteamericano Clement Greenberg publicaba su ensayo Modernist Painting en 1960. La muerte de Jackson Pollock solo unos pocos años antes, suponía el fin de una amistad y una relación profesional artista-crítico traducida en el final de la pintura all-over (o de campo expandido), tal y como la definiría Greenberg ${ }^{14}$. Para el crítico norteamericano, "Pollock rebasó el cubismo tardío de donde procedía" controlando su gestualidad física a través de una pintura "diáfana, emocionante y homogénea" 15 . Las conexiones de Pollock con el cubismo analítico estuvieron siempre presentes en el pensamiento modernista de Greenberg. Éste hablaba de cómo el norteamericano había tomado de Picasso y Braque el recurso de los planos-faceta y salpicaduras puntillistas de color de las obras de 1909 a 1913 y los había hecho evolucionar hacia un plano mucho más físico, en torno al trabajo con la superficie material del lienzo. Pocos años más tarde del fallecimiento del artista del expresionismo abstracto, en los 60, el arte Pop empezaba a despuntar y Greenberg se manifestaba enormemente contrario a éste. Estas nuevas tendencias artísticas y culturales encajaban en su definición de lo "kitsch" como falsos sucedáneos producidos por las modernas sociedades de consumo ${ }^{16}$. Alineado con Greenberg, Castillejo definiría ésta como "trash cultu$r e$ " en sus textos sobre arte moderno que trataremos más adelante ${ }^{17}$.

El escritor, que era conocedor de todos estos debates acerca del arte y la cultura, continuaría con su carrera diplomática, su pasión por el coleccionismo y sus constantes viajes a Nueva York, Madrid, Zúrich o París. En 1964 sería destinado como Secretario de primera clase a la Embajada de Argel y dos años después comenzó su corta pero reveladora etapa dentro del colectivo de arte conceptual Zaj.

\section{Conexión con el arte experimental y Zaj}

No es nuestra intención en este texto desarrollar en profundidad qué supuso el fenómeno Zaj, y tratar de explicar grosso modo sus presupuestos conceptuales principales es también tarea arriesgada, pues sabemos que nos dejaremos muchos conceptos y hechos por narrar. Aun así, contextualizaremos brevemente su genealogía artística: el surgimiento de Zaj se caracteriza por unas prácticas transgresoras que rompen con toda etiqueta estilística, quebranta la delimitación de los medios artísticos y tiene como común denominador a la acción dirigida desde lo cotidiano. Surge en un contexto internacional de experimentación posterior a la Segunda Guerra Mundial y, en España, en un entorno marcado por un régimen dictatorial, aunque ya en su etapa aperturista, donde sus integrantes debían sortear la censura. Se trata de una etapa en el

11 Información extraída a partir de la entrevista personal que mantuve con José Luis Castillejo el 3 de mayo de 2010 . Ese año nos reunimos durante varias horas en Madrid y en dos ocasiones para hacer un repaso a su trayectoria artística y personal.

12 Idem.

13 Idem.

14 Clement Greenberg, La pintura moderna y otros ensayos, Madrid, Siruela, 2006, p. 77.

15 Ibidem, p. 78.

16 Ibidem, p. 30.

17 José Luis Castillejo, Ensayos sobre Arte y Escritura, Madrid, Ediciones La Bahía, 2013, p. 29. El conjunto de ensayos de Castillejo publicados en Ediciones La Bahía en 2013 procede de un compendio de originales del escritor que fueron escritos en diversos momentos entre la década de los 90 y los 2000. Castillejo me facilitó en 2010 una copia de los originales. 
arte caracterizada por las manifestaciones conceptualistas surgidas en las artes visuales que debido a su gran variedad de tipos de manifestaciones se antoja de difícil concreción, pero que tienen en la figura de Marcel Duchamp un "padre" inspirador común. Las creaciones del francés de principios del siglo XX reformularían conceptos tan esenciales como el de "artista", "obra de arte" o incluso el rol del espectador, acercando la vida al mundo más institucional de la creación artística, algo de lo que partió también Zaj. Contrario al formalismo y de tendencia desmaterializadora, podemos afirmar también que el origen de las creaciones de Zaj estaba en buena medida en el mundo de la música (Juan Hidalgo había estudiado la carrera de piano) y en la obra de John Cage. El creador norteamericano, influido por la filosofía oriental revolucionó la creación sonora contemporánea por medio de su trabajo en torno a la música aleatoria o música controlada por azar (véase el uso del I Ching para delimitar sus creaciones), introdujo el concepto de vacío y silencio en la composición musical o creó su Piano Preparado, que transformaba el sonido de este instrumento por medio de la inserción de objetos de desecho en su interior. En España, fue crucial para el arte la toma de contacto de Juan Hidalgo y Walter Marchetti -que ya conocían la música dodecafónica, concreta y electrónica ${ }^{18}$ - con el creador norteamericano en 1958 en la ciudad alemana de Darmstadt, donde estaba la prestigiosa escuela en el campo de la innovación musical del mismo nombre, y donde se celebraban los importantísimos Internationale Feirenkurse für Neue Musik (festivales internacionales de la nueva música). Unos años más tarde, tras una etapa de formación europea, en 1964, Zaj fue creado de manera oficial en Madrid por parte de Juan Hidalgo, Walter Marchetti y Ramón Barce. Su espíritu abierto y nómada, y su interés por escapar a que se les definiera o clasificara de algún modo, puede leerse en uno de sus más célebres cartones elaborado por Marchetti: "Zaj es como un bar, la gente entra, sale, se toma una copa y deja una propina".

Castillejo fue uno de esos nómadas heterodoxos que entró y salió del colectivo. El escritor viajó constantemente a España y Francia entre 1964 y 1967. En España, a través de su amistad con la galerista Juana Mordó, compró obra de creadores españoles como Manolo Millares o Pablo Serrano. Fue en el estudio de este último donde Castillejo conoció por primera vez a Juan Hidalgo. Tras aquel encuentro, el diplomático invitó a Hidalgo a pasar el verano de 1966 a Argel. Aquel encuentro estival desembocó en el concierto Noche Zaj en Argel, que tuvo lugar en la residencia del diplomático y acabó de asentar en Castillejo su interés por la escritura experimental ${ }^{19}$. Ese verano Castillejo, guiado por las indicaciones de Hidalgo, realizó el libro Zaj La caída del avión en el terreno baldio e Hidalgo su Viaje a Argel ${ }^{20}$. Un año más tarde, Hidalgo volvería a viajar a Argel a pasar el siguiente verano.

La inmersión de Castillejo en la práctica artística rupturista es indudable que se debe a la figura de Juan Hidalgo y de Zaj. Varios años antes de que el escritor realizara sus primeros libros Zaj, en 1961, Hidalgo había empezado a escribir en papeles sueltos pequeñas frases, recuerdos o instrucciones, que luego compilaba en forma de libro recopilatorio. A éstos los denominó etcéteras o también algos ${ }^{21}$, composiciones poéticas con una base de inspiración en John Cage, donde el azar se utilizaba como parte del proceso creativo, y también servían de base para la realización de acciones performativas. Este interés por la experimentación en el campo de la escritura y el arte de acción, más allá del informalismo pictórico, fue lo que atrajo a Castillejo hacia Zaj.

18 Juan Hidalgo citado por Llorenç Barber en Zaj (Comis. José Antonio Sarmiento), Madrid, MNCARS (Catálogo de exposición celebrada del 23 de enero al 21 de marzo de 1996), 1996, p. 37.

19 Maderuelo, 2014-15, p. 75.

20 José Antonio Sarmiento hace un análisis sobre la composición de ambos libros de Castillejo e Hidalgo en José Antonio SARMiento GarcíA, La Otra Escritura: la poesía experimental española, 1960-1973, Cuenca, Universidad de Castilla la Mancha, 1990, pp. 19-20.

21 Buena parte de estos etcéteras o algos (este último término podría estar relacionado con el nombre de la editorial de Dick Higgins, Something Else Press) de Juan Hidalgo están recopilados en: Juan HidALGO, Juan Hidalgo de Juan Hidalgo (1961-1991), Madrid, Pre-Textos, 1990. 


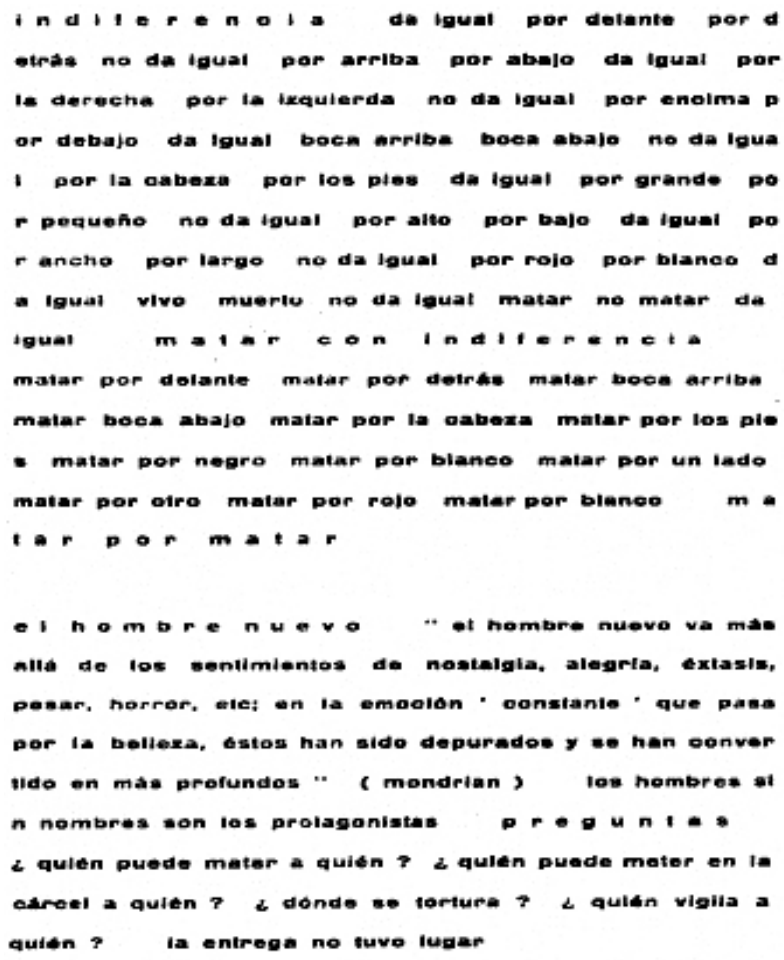

Fig. 1. José Luis Castillejo, La Política, 1967. 270x215 mm, Madrid, colección particular.

Los dos años comprendidos entre 1966 y 1967 fueron para Zaj de intensísimo trabajo, con acciones alrededor de todo el mundo. Castillejo participó en la elaboración de muchas de estas acciones ${ }^{22}$ contribuyendo con textos escritos específicamente para piezas como Egolatría del año $1967^{23}$ o A dice B de $1968^{24}$. Durante ese período de tiempo, como afirma José Antonio Sarmiento, "fue José Luis Castillejo, quien intentó desarrollar el proyecto más ambicioso en torno a la escritura realizado en nuestro país" ${ }^{25}$. El escritor realizó en 1967 el libro Zaj La Política, que fue publicado en 1968 (fig. 1).

Este período frenético terminó ese año, pues las relaciones entre Castillejo e Hidalgo acabaron por romperse. El motivo de este alejamiento aún sigue sin ser refrendado por medio de fuentes documentales, pero el escritor aseguraba en una entrevista mantenida con él en 2010 que Hidalgo le había expulsado de Zaj porque Castillejo seguía manteniendo un gran interés por la pintura, un medio que para Zaj formaba parte de un sistema mercantilista del arte con intereses espurios ${ }^{26}$. Juan Antonio González Fuentes amplía esta información de la supuesta expulsión de Castillejo refiriéndose a un interés de nuestro autor por ampliar el

\footnotetext{
22 En este sentido el escritor Fernando Millán alude a las experiencias de Castillejo durante su etapa en Zaj en Fernando MiLLÁN, Escritores Radicales, Madrid, Bubok, 2013, pp. 89-96. Millán habla de aspectos más bien personales relacionados con el escritor.

${ }_{23}$ Zaj (Comis. José Antonio Sarmiento), Madrid, MNCARS (Catálogo de exposición celebrada del 23 de enero al 21 de marzo de 1996), 1996, p. 15.

${ }^{24}$ Zaj. Colección Archivo Conz (Archivo Conz), Madrid, Círculo de Bellas Artes (catálogo de la exposición celebrada del 5 de febrero al 22 de marzo de 2009), 2009, p. 55.

25 Hidalgo, 1990, p. 20.

26 El 3 de Mayo de 2010 entrevisté a Castillejo en su residencia de Madrid. La entrevista puede leerse en "Entrevista con José Luis Castillejo", Luis Cáceres Cantero, entrada de blog publicada el 15 de marzo de 2019 https://luiscacerescantero.blogspot.com/2019/03/entrevista-con-jose-luis-castillejo.html [Consulta: 15 de marzo de 2019].
} 
grupo a más miembros, algo con lo que no estaba de acuerdo el artista canario ${ }^{27}$. Según Castillejo, Juan Hidalgo supuso para él su "liberador" en dos ocasiones ${ }^{28}$. La primera de ellas en el momento en que entró en Zaj y la segunda en el momento de su abandono del mismo.

\section{Greenberg o la defensa a ultranza del modernismo}

En aquella década de los 60 Greenberg había basculado su pensamiento hacia lo que él denominaría "espacio óptico", un término que abandonaba en cierta manera la gestualidad del action painting y el dripping de Pollock por la pura visualidad cromática de Morris Louis y Kenneth Noland. Arrancaba así una segunda generación del Grand Style norteamericano que se desarrollaría de manera exponencial con el arte de la pintora Helen Frankenthaler. La relación de Castillejo con este círculo de artistas y críticos fue constante durante los años 80, años en los que dejó de hacer escritura experimental.

Al otro lado del Atlántico, en París, a finales de los años 60, surgiría el colectivo Supports/Surfaces, un grupo de artistas cuya conceptualización vino determinada por el pintor Marc Devade y el filósofo y escritor Marcelin Pleynet. Este movimiento aglutinó a artistas como Louis Cane, el referido Marc Devade, Daniel Dezeuze o Claude Viallat entre los años 1969 y 1972. Les unía la reflexión sobre los procesos propios de la pintura. Los Supports/Surfaces llevaron a cabo una deconstrucción del medio pictórico en un momento en que éste estaba siendo denostado por muchos. Estos artistas cuestionaron los materiales, soportes, lugares de exposición e incluso al público que seguía apostando por la pintura, no con el fin de liquidarla, sino con el fin de revitalizarla. Conectaron así con el estudio que autores post-estructuralistas como Jacques Derrida o Julia Kristeva estaban llevando a cabo en el campo del lenguaje y la escritura. Castillejo, acompañado del joven pintor Carlos León ${ }^{29}$, entabló contacto con todos ellos en torno a 1972 a través del galerista Daniel Templon ${ }^{30}$, adquiriendo también obra de muchos ${ }^{31}$.

La introducción de Europa y París en la disputa por controlar el arte moderno a partir de después de la Segunda Guerra Mundial era un debate que para el propio Greenberg aún en los 70 y 80 estaba presente. Como recoge Serge Guilbaut en De cómo Nueva York robó la idea de arte moderno, Greenberg en la década de los años 30 había sido uno de los integrantes de ideología izquierdista-trotskista de Partisan Review y en la década de los 50 y los 60, en un giro conservador e "idealista" en su pensamiento ${ }^{32}$, trabajó al servicio del Departamento de Estado de los EEUU ${ }^{33}$ con el fin de impulsar la pintura del expresionismo abstracto norteamericano en el resto del mundo durante la etapa más dura de la Guerra Fría. Así, por ejemplo, en 1952 Jackson Pollock era mostrado por primera vez en el estudio de Paul Facchetti en París, o Willem de Kooning se exponía en la muestra Un Art Autre (un arte otro), ambas organizadas por Michel Tapié.

\footnotetext{
27 RiVIÈRE, 2018, p. 31.

28 Esta información ha sido sacada de una entrevista que mantuve con Castillejo el 3 de mayo de 2010 en su residencia de Madrid.

${ }^{29}$ La visión artística como pintor-escultor de Carlos León en aquella década animó a Castillejo a realizar varios libros aún inéditos donde el trazo y la gestualidad cercana al automatismo surrealista están aún por estudiar.

${ }^{30}$ La galería Templon fue inaugurada en 1966 en París. Por sus salas han pasado artistas como Jean-Michel Basquiat, Willem de Kooning, Richard Serra o Andy Warhol. En 1972 con la escritora, comisaria y crítica Catherine Millet, Templon cofundaría la revista Art Press.

31 Información obtenida a partir de una entrevista mantenida el 5 de diciembre de 2017 con el pintor Carlos León, amigo íntimo de Castillejo desde finales de los 60.

32 Pedro DE Llano, "Vanguardia y kitsch' en el universo del totalitarismo", Anuario del Departamento de Historia y Teoría del Arte, vol. 25 (2013), pp. 75-91.

33 Serge Guilbaut, How New York Stole the Idea of Modern Art, Chicago, University of Chicago Press, 1985, p. 231; véase también Bajo la bomba: el jazz de la guerra de imágenes transatlántica, 1946-1956. (Comis. Serge Guilbaut), Madrid y Barcelona, MACBA y MNCARS (catálogo de exposición celebrada del 4 de octubre de 2007 al 7 de enero de 2008), 2007.
} 
En una crítica de febrero de 1947, Greenberg hacía patente, con argumentos puramente subjetivos, su predilección por el arte de Jackson Pollock por encima de la obra de Jean Dubuffet en una muestra inaugurada en la galería Pierre Matisse de París. En la crítica publicada sobre la exposición, Greenberg afirmaba que Pollock era "americano, más duro y brutal, y al mismo tiempo un artista más completo", calificándolo como un artista "menos conservador y menos tradicional que Dubuffet". De este último simplemente afirmaba al final del texto que su logro histórico más importante residía en "haber preservado la pintura de caballete para la generación de autores posteriores a Picasso"34.

Tal y como recoge Eva Cockcroft en su ensayo Abstract Expressionism, Weapon of the Cold War, el expresionismo abstracto se vendió como el contraste perfecto al regimentado, tradicional y corto de miras realismo socialista. Para la autora, el arte americano se presentó a las masas como nuevo, fresco y creativo, artísticamente vanguardista y original. Éste era mostrado como una potencia cultural que podía competir con París, algo que fue posible porque Pollock, así como muchos otros artistas vanguardistas norteamericanos, habían abandonado su interés en el activismo político ${ }^{35}$. Si querían seguir participando en las muestras nacionales e internacionales que se organizaban por ejemplo desde el MOMA, no podían evidenciar de ninguna manera una ideología cercana al comunismo.

De las cartas mantenidas entre Castillejo y Greenberg se deduce que aquella batalla por hacerse con la hegemonía cultural y artística contra Francia seguía vigente en la década de los años 80 para el crítico norteamericano, cuando éste afirmaba tener cierta alergia a la teoría en el arte proveniente de París y de los círculos de Pleynet y la revista $\mathrm{Tel} \mathrm{Que}^{36}$. Esta toma de posición contraria a la teoría en el arte de Greenberg resulta paradójica, en cuanto él mismo fue un importante teórico dentro de la historia del arte del siglo XX. El norteamericano trataba en aquellos años de poner en la escena internacional incluso a una tercera generación de creadores jóvenes del expresionismo abstracto como Yvonne Muller, Susan Roth, Walter Darby Bannard o Joseph Drapell ${ }^{37}$, muchos de ellos también apoyados por Kenworth Moffett ${ }^{38}$, crítico y amigo de Greenberg, cuando el formalismo había sido ya ampliamente superado y Greenberg había dejado de ser el todopoderoso e influyente teórico que había sido desde finales de los años 30 .

\section{El pensamiento modernista de Castillejo}

La primera toma de contacto personal de Castillejo con Greenberg fue en junio de 1981. Castillejo conoció al crítico norteamericano a través del galerista André Emmerich. En abril de ese año, Emmerich recibió una carta del español comentándole su próximo viaje a Nueva York desde Lagos (Nigeria) donde estaba destinado con la intención de visitarle ${ }^{39}$ (figs. 2 y 3). Castillejo también le pedía un favor a Emmerich: quería conocer a Clement Greenberg en persona, según decía él, porque algunas personas en España estaban interesadas en organizar unas conferencias donde participara ${ }^{40}$. Hay que recordar que Castillejo estaba familiarizado con los textos e ideas del crítico norteamericano desde hacía muchos años, aunque nunca se hubieran conocido.

\footnotetext{
34 Clement Greenberg, The Collected Essays and Criticism. Volume 2, Arrogant Purpose. 1945-1949, Chicago, Edited by John O'Brian, 1986, pp. 122-125.

35 FAscina, 2000, p. 151.

36 Carta de Greenberg a Castillejo del 6 de diciembre de 1981.

37 Todos estos artistas están referenciados en la correspondencia mantenida en los 80 entre Greenberg y Castillejo.

38 La figura del crítico Kenworth Moffett es mencionada por el pintor Carlos León durante nuestra entrevista mantenida el 5 de diciembre de 2017. De él dice el artista que "era más greenberguiano que el propio Greenberg". También Moffett aparece referenciado en la correspondencia entre Greenberg y Castillejo. Carta del 29 de julio de 1982.

39 Carta de Castillejo a André Emmerich del 5 de abril de 1981.

40 No existe constancia de que se llegaran a realizar las conferencias de las que habla Castillejo en su correspondencia con André Emmerich.
} 

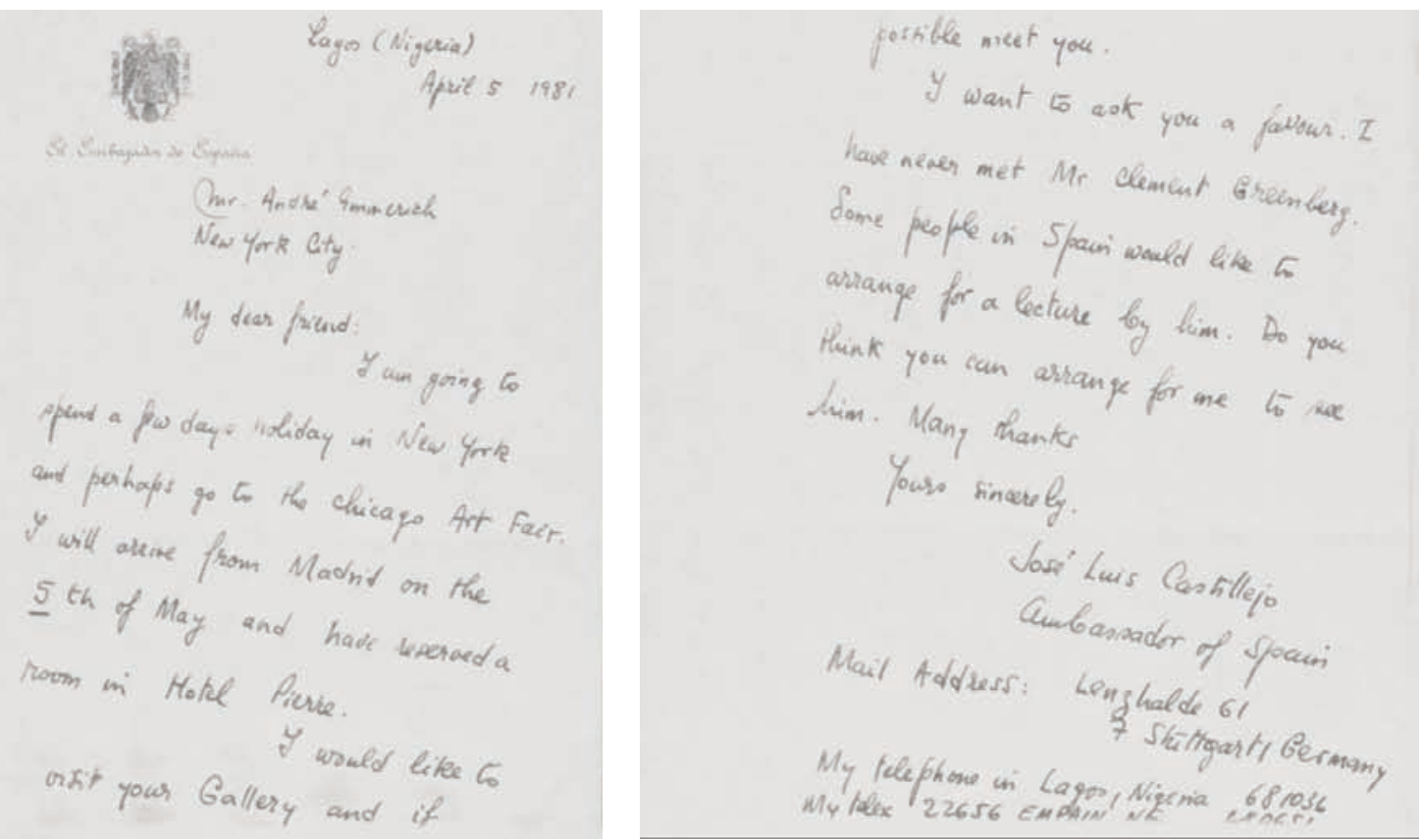

Fig. 2. José Luis Castillejo, Carta entre Castillejo y el galerista André Emmerich, 5 de abril de 1981. Washington, Archives of American Art del Smithsonian de Washington D.C. [Series 3. Correspondence, 1937-1983. Folder 23].

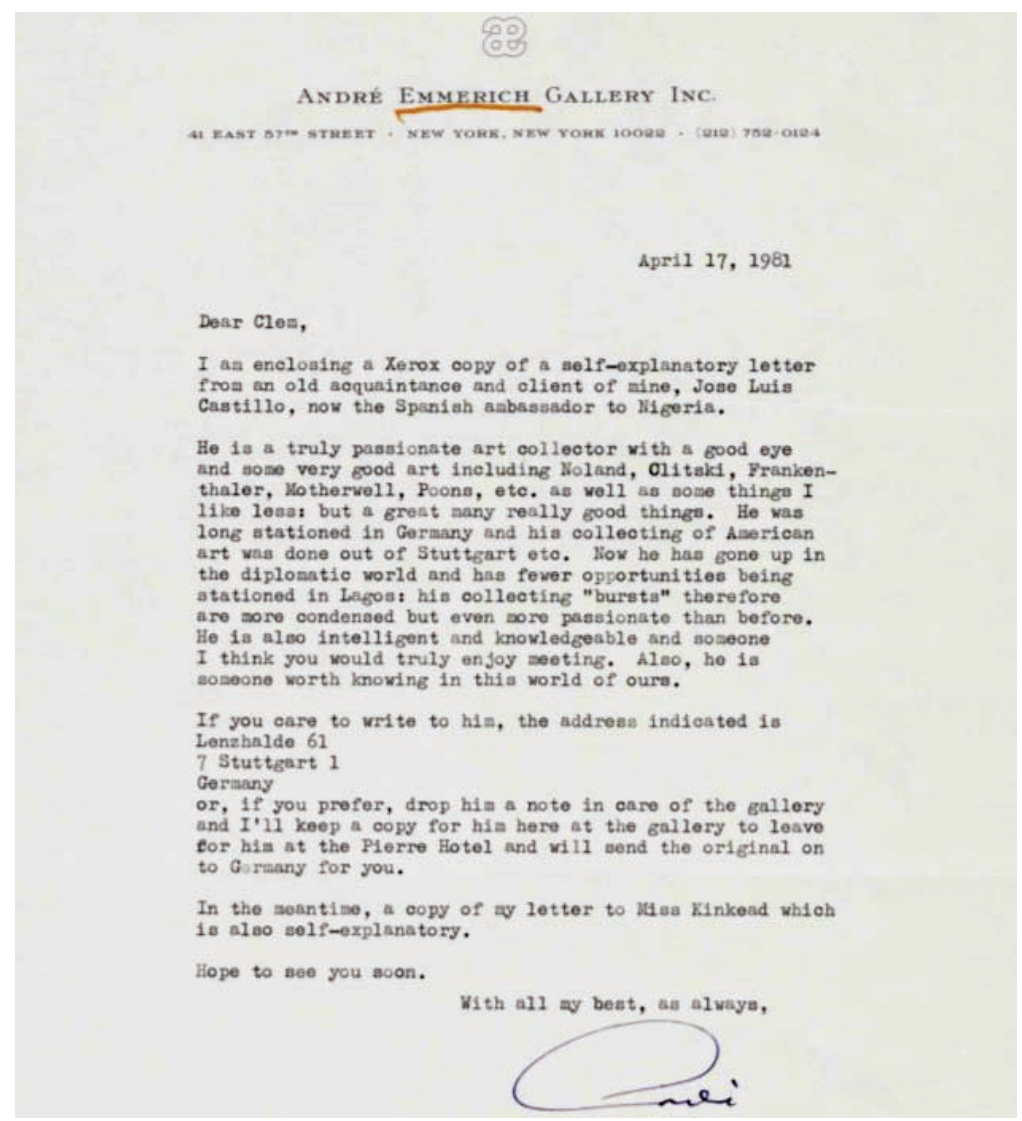

Fig. 3. André Emmerich, Carta de André Emmerich a Clement Greenberg, 17 de abril de 1981. Washington, Archives of American Art del Smithsonian de Washington D.C. [Series 3. Correspondence, 1937-1983. Folder 23]. 
Empezaba así un intercambio de cartas entre ambos que duraría hasta 1983. En ellas, como iremos analizando a continuación, debaten sobre muchos temas que atraviesan la pintura americana y europea de los 60,70 y 80 y el estado de la cultura en esos años, con particular interés en el mundo de las galerías. Castillejo se presenta como admirador de Greenberg desde el primer momento, ensalzando al crítico y situándole como su mentor intelectual ${ }^{41}$. También desde un primer momento vincula su escritura post-Zaj a los cánones modernistas, llegando a definir por entonces The Book of I's ${ }^{42}$, editado en 1969 y reeditado en 1976 en la ciudad alemana de Constanza, como un libro modernista ${ }^{43}$.

Términos como el de medium-specificity ${ }^{44}$, pureza o materialismo, lo perceptual u óptico o la diferencia entre vanguardia y kitsch, referenciales dentro de las premisas modernistas y adoptadas por Castillejo en su trabajo, están presentes en el intercambio personal e intelectual de Castillejo y Greenberg de los años 80, inscribiéndose en los términos de lo que se ha venido a denominar "modernismo tardío" o "late modernism".

Uno de los debates que sobrevuelan toda la correspondencia de Castillejo con Greenberg es el de la supervivencia de la llamada "alta cultura" en un contexto marcado por la cada vez más extendida sociedad de consumo. En una misiva de junio de 1981, tras haber intercambiado algunas visitas a galerías de Nueva York, Castillejo pregunta a Greenberg por los artistas que el español debería seguir, para a continuación afirmar: "The art world of the magazines and fairs is not where seriousness is to be found. I realize that even now modernism is underground" 45 . Castillejo busca el juicio estético e intelectual de Greenberg con la intención de detectar a los artistas que están realizando arte en consonancia con los ideales del modernismo. Greenberg contesta a Castillejo diciéndole que seguramente ya conoce a esos creadores que están despuntando en la ciudad de los rascacielos, y le remite a las galerías de Emmerich, Knoedler u O'Reilly. Además, le enumera una lista de escultores que están trabajando en la línea de David Smith o Anthony Caro, como Willard Boepple, Peter Reginato o James Wolfe ${ }^{46}$.

Este interés de Castillejo por el high art, o el Grand Style greenberguiano como lo denomina en numerosas ocasiones el escritor en sus cartas, demuestra su línea de pensamiento estético e intelectual, visible también en las obras que había coleccionado desde finales de los 60 y que todavía seguía adquiriendo en los 80: abstracción pictórica americana y europea de post-guerra. En cambio, el trash art o trash culture, como denominaba Castillejo en su ensayo de La Pintura Moderna ${ }^{47}$ al arte producto de la industrialización y el auge de la sociedad de consumo masiva, le producía un gran rechazo (fig. 4). Según el autor, este tipo de creaciones "trae consigo la pérdida del gusto debida a la falta de gusto de las nuevas clases, así como la creación del Kitsch como arte industrial sustitutivo, característico de la sociedad industrial. El arte de un nuevo fetichismo o culto sintético del objeto"48.

La naturaleza nociva del kitsch o trash culture para Castillejo ya había sido argumentada por Greenberg en su famoso texto "Vanguardia y Kitsch" publicado en Partisan Review en 1939, un escrito fundamental dentro de la crítica artística de lo que quedaría del siglo XX. En aquel momento el autor norteamericano no se centraba en confrontar el arte de academia con el de vanguardia, sino en contraponer la creación de vanguardia con la cultura de masas. Para Greenberg el arte de las primeras vanguardias, que para él no englo-

\footnotetext{
41 Carta de Castillejo a Greenberg del 18 de junio de 1981.

42 Javier Maderuelo, The book of I's, de Jose Luis Castillejo. [en línea], http://arteyparte.com/arte-y-edicion-108-the-bookof-is-de-jose-luis-castillejo [Consulta: 15 noviembre de 2017].

43 Carta de Castillejo a Greenberg del 24 noviembre de 1981.

44 En 1960 Greenberg publica su ensayo La Pintura Moderna donde analiza la idea de la especificidad de cada medio artístico, donde el artista debe ceñirse exclusivamente a su área de competencia. Grosso modo, el medio para Greenberg hace referencia a los elementos materiales que cada forma artística posee. Este texto se puede encontrar en Clement GREENBERG, The Collected Essays, Vol.4, Madrid, The University Chicago Press, 1993, pp. 85-94.

45 Carta de Castillejo a Greenberg del 18 de junio de 1981.

46 Carta de Greenberg a Castillejo del 4 de agosto de 1981.

47 Este texto lo escribió Castillejo para una conferencia en la Casa Galicia de Madrid en 1999.

48 CAstillejo, 2017, p. 27.
} 


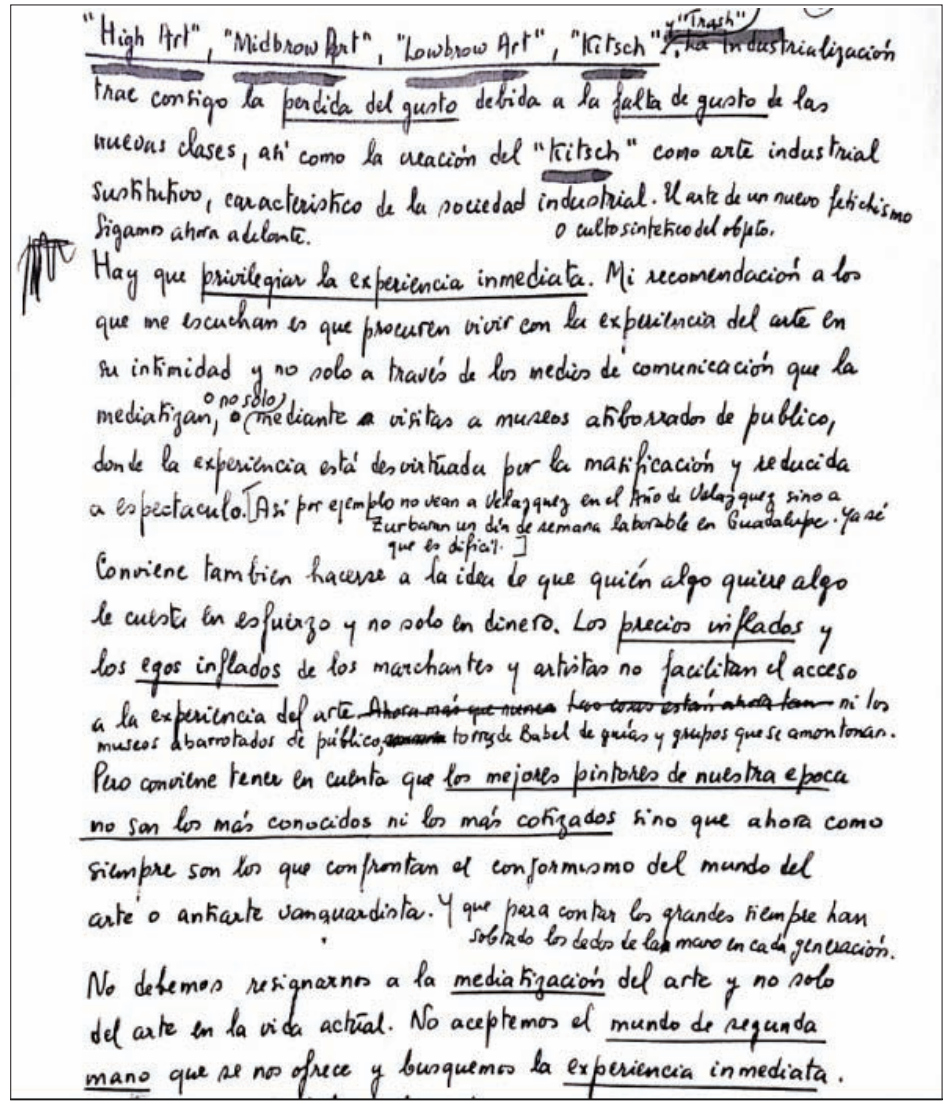

Fig. 4. José Luis Castillejo, Fragmento manuscrito de La Pintura Moderna (texto escrito para Conferencia en la Casa de Galicia), 1999. 210x297 mm, Madrid, colección particular de la familia del artista.

baba la línea surrealista, dadaísta o constructivista del arte, sino que partía desde Manet, Cézanne, el cubismo, las vanguardias formalistas y acababa en el expresionismo abstracto, entraba dentro de lo que se podía considerar como alta cultura. El problema era la "contaminación" de lo masivo ${ }^{49}$ y lo popular como falsos sucedáneos de esa alta cultura a partir de finales de los años 30. Sobre este aspecto Castillejo comentó: "recomiendo a los que me leen que procuren vivir con la experiencia del arte en su intimidad y no sólo a través de los medios de comunicación que la mediatizan, o no sólo mediante visitas a museos atiborrados de público, donde la experiencia está desvirtuada por la masificación y reducida a espectáculo ${ }^{50}$ ". En las cartas con Greenberg, Castillejo también calificaba de culto masivo la atención mediática y espectacular dada a la figura de Picasso. Para el escritor la masificación del público que acudía a las exposiciones de artistas 'estrella' como el malagueño, corrompía el verdadero fin del arte, que tenía que ver con la cultura y la reflexión profunda y no con la sociedad del espectáculo ${ }^{51}$.

49 Guilbaut, 1985, p. 81.

50 CAstillejo, 2013, p. 31.

51 La crítica a la sociedad de consumo que produjo como resultado el kitsch para Greenberg tiene un importante paralelismo en el concepto de industria cultural ideado por Theodor Adorno y Max Horkheimer unos años más tarde entre 1944 y 1947, cuando ambos escribieron su célebre artículo La industria cultural. Iluminismo como mistificación de masas. Ambos alemanes y exiliados en Estados Unidos debido al avance del Nazismo en su país de origen, analizan esencialmente la industria del entrenamiento o amusement del país norteamericano de acogida. Este parecido conceptual entre Greenberg y los autores alemanes es analizado 

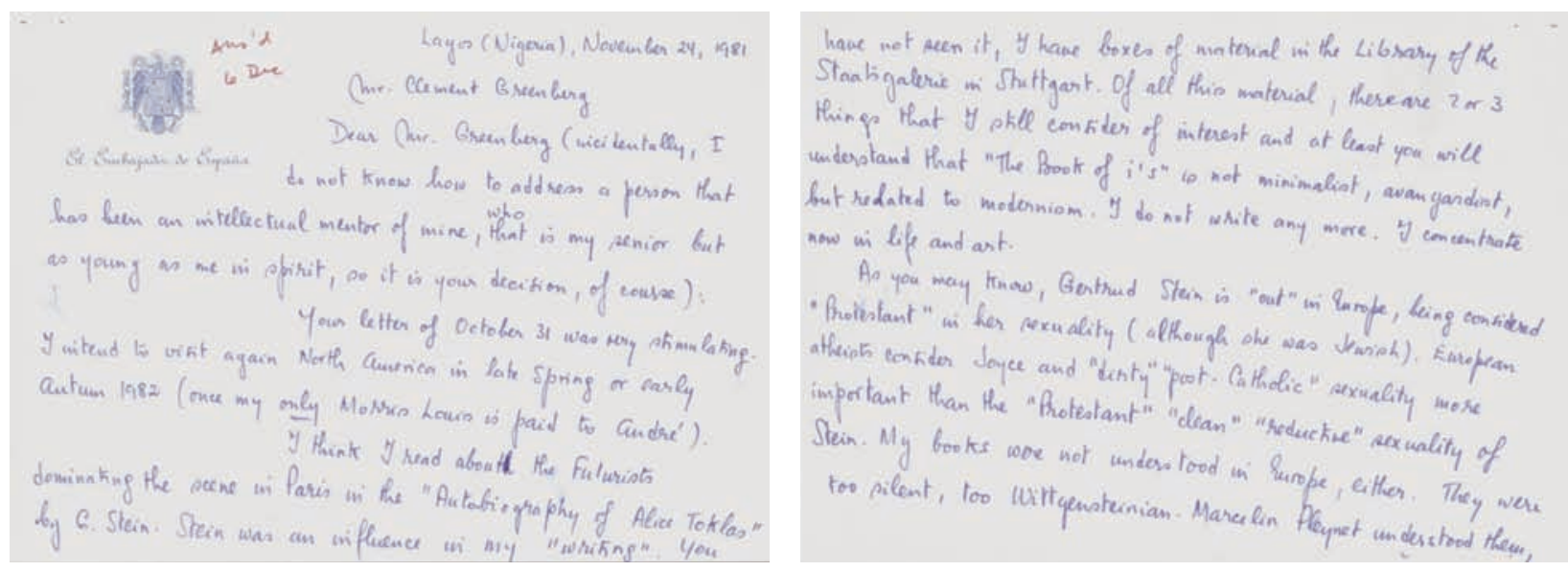

Fig. 5. José Luis Castillejo, Carta de Castillejo a Clement Greenberg, 24 de noviembre de 1981. Washington, Archives of American Art del Smithsonian de Washington D.C. [Series 3. Correspondence, 1937-1983. Folder 23].

Las alusiones de Castillejo a lo que entendía Greenberg como arte de vanguardia en la correspondencia son constantes. El escritor presta especial atención al Cubismo y a la figura de Gertrude Stein, que fue enormemente influyente en su trabajo ${ }^{52}$. Castillejo hace una conexión entre los pintores europeos contemporáneos como Louis Cane, Marc Devade o Daniel Dezeuze y los cubistas de principios de siglo. Afirma que los pintores franceses de los 70 eran desconocidos por "aparecer en un momento no propicio" para que la sociedad reconociera su importancia, al igual que Picasso y Braque a inicios de siglo fueron eclipsados por los futuristas, más reconocidos por el público: "to show art in the wrong context or moment will add to a misunderstanding. The same thing happened, at least Gertrude Stein said so, when the Futurists occupied the art scene and the public did not know about the cubist works of Braque and Picasso"53 (fig. 5). Así, Castillejo en su correspondencia toma referencias históricas del arte del pasado para desarrollar argumentaciones afines a las del modernismo greenberguiano. La creación artística para Greenberg solo podía darse atendiendo a las referencias intelectuales y estéticas previas al momento del auge de los mass media en el $\operatorname{arte}^{54}$. La escritura de Castillejo, según su autor, se situaba dentro de esa misma referencialidad histórica.

Castillejo vinculaba su forma de trabajar a la que habían seguido en la pintura artistas como Manet, Matisse o el par Braque-Picasso en su etapa del cubismo analítico. Acerca de este período del cubismo afirmaba que "fue la primera etapa del movimiento". Para continuar diciendo: "Viendo sus obras maestras grises y marrones, y la importancia de las líneas del dibujo (la reja cubista producida por el análisis del objeto), se advierte pronto hasta qué punto el cubismo aparece como un arte mental, aunque no conceptual, porque en sus creaciones sigue siendo pintura, escultura, arquitectura..., y no solo una idea" ${ }^{55}$. De Matisse decía:

...es el mejor pintor del siglo XX. Como pintor, no como mito, no como celebridad. Matisse solo creó arte. Picasso creó además su propio mito... Para Matisse la pintura no es literatura. Una pintura que solo pueda ser leída como literatura termina siendo efímera en cuanto consabida. Deja de ser experiencia y el arte es propiciatorio de la experiencia ${ }^{56}$.

en profundidad en: Thierry DE Duve, Clement Greenberg entre líneas (trad. Pilar Vázquez Álvarez), Santa Cruz de Tenerife, Asociación para el cuidado de las buenas formas, 2005, p. 43.

52 Castillejo tradujo al español el libro Gertrude StEIN, Retratos, Barcelona, Tusquets-Cuadernos Marginales, 1974.

53 Carta de Castillejo a Greenberg del 29 de septiembre de 1981.

54 GreENBERG, 2006, p. 120.

55 Ibidem, p. 39.

56 Ibidem, p. 34. 
Estos autores, que eran también referentes del modernismo greenberguiano, ilustraban el discurso formalista basado en el medio diferencial defendido por el crítico norteamericano, algo con lo que Castillejo comulgaba conceptualmente desde su salida de Zaj ${ }^{57}$.

El medio específico de Castillejo era la escritura, lo que le distanciaba de Greenberg quien se ceñía casi exclusivamente al medio pictórico y, en segundo término, a la escultura. Para Castillejo la escritura, como para Greenberg la pintura, no podía ser contaminada por las demás artes. El alejamiento paulatino de la escritura experimental de esos parámetros y su contaminación de la cultura popular, de consumo y masiva supuso según nuestro autor el fin de la evolución de la misma. El escritor entendía su trabajo como un proceso de autoanálisis crítico. La obra post-Zaj de Castillejo de finales de los 60, donde ya deja evidenciado en varios textos teóricos su inmersión conceptual en el modernismo de Greenberg, reflexiona acerca de qué es la escritura con el fin de reafirmarla dentro de su propio medio.

El debate en torno a la aparición de las denominadas críticamente por Greenberg en los años 60 (un Greenberg más cercano al katismo y más conservador en sus posturas culturales y políticas) como las Novelty Arts $^{58}$, donde se englobaban todas las nuevas creaciones cercanas al Pop, el Minimal, el Conceptual o el Land Art entre otros, acercaban el arte por su efecto falsificado y espurio, producido mediante fórmulas de modo calculado para producir una determinada respuesta del espectador y alejadas de lo que debía ser la experiencia artística para Greenberg, al estatuto del kitsch de finales de los años 30, al que aludía constantemente Castillejo en sus escritos post-Zaj. Los artistas de esta corriente eran meros imitadores superficiales de lo que debía ser el arte auténtico. En su emulación falsificada del arte de calidad modernista se habían abandonado las reglas esenciales del arte.

Muchos de los conceptos que elaboró Greenberg en los años 60 tenían como principal objetivo combatir esta falsa producción que abocaba el arte a la literalidad y el nominalismo artístico de corte anti-ilusionista muy presente, a su juicio, en el arte Minimal. El objetivo del crítico era que la pintura abstracta y de calidad modernista que defendía no fuera entendida como un objeto literal, donde la sola presentación de sus materiales específicos literales lo acercaran al Minimal y por tanto pudieran caer en un nominalismo artístico. Para conseguirlo, evocó la importancia del concepto de "ilusionismo", un término de difícil concreción en la teoría greenbergiana, pero que se fundamenta, grosso modo, en ciertos aspectos del orden de lo representado como las figuras, el espacio o los volúmenes en el caso de la pintura y que se acerca al concepto de contenido, no narrativo, de la obra. Un arte de calidad modernista, para Greenberg, debía basarse en la relación de tensión y equilibrio entre un ilusionismo bueno (el que se pone de acuerdo con la naturaleza del medio artístico y sólo usa recursos propios de éste, sin imitar los de ningún otro) y su concepto de lo literal (lo físico material de los componentes de la obra $)^{59}$. El equilibrio de fuerzas entre ambas era lo que podía otorgar a la obra un juicio positivo de calidad en la visión del crítico norteamericano. Esto enlazaba también con los principios de pura visualidad de los primeros formalistas, sobre todo al referirse a la especificidad del medio de la pintura, alejado de todo lo que tuviera que ver con lo táctil, performativo o teatral que pudiera contaminar la pureza retiniana del

57 Ibidem, p. 25. La primera página del Ensayo sobre La Pintura Moderna de Castillejo empieza con una referencia al mediumspecificity de Clement Greenberg o especificidad diferencial para Castillejo. Toda una declaración de intenciones acerca de cómo entendía la práctica artística nuestro autor.

58 En su texto "Recentness of scultpture" de 1967, Greenberg rechaza el arte minimalista al considerarlo alejado del arte auténtico de calidad. El novelty art es un objeto de novedad que provoca nada más que una sorpresa momentánea superficial en el espectador. Carece de la entidad estética de gusto basada en la conexión y comparación con las obras maestras de la vanguardia. Véase: GREENBERG, 1993, pp. 250-53. En referencia a este mismo debate véase: James MeYER, "Recentness of sculpture", en Minimalism. Art and polemics in the sixties, New Haven y Londres, Yale University Press, 2001, pp. 211-221; Francisca PÉREZ CARREÑO, "Greenberg, Fried y el caso del arte minimal", en Arte Minimal: objeto y sentido, Madrid, Antonio Machado libros, 2003, pp. 173-205.

59 Esta tensión entre "lo literal y la ilusión" viene recogida en el referencial escrito de Greenberg Modernist Painting (1960). GREENBERG, 1993, p. 86-87.

${ }^{60}$ Greenberg defiende un análisis de la escultura desde una concepción óptica y no táctil en su texto Sculpture in our times (1958) traducido al español en: Clement Greenberg, Arte y Cultura, Barcelona, Gustavo Gili, 1979, pp. $135-137$. 


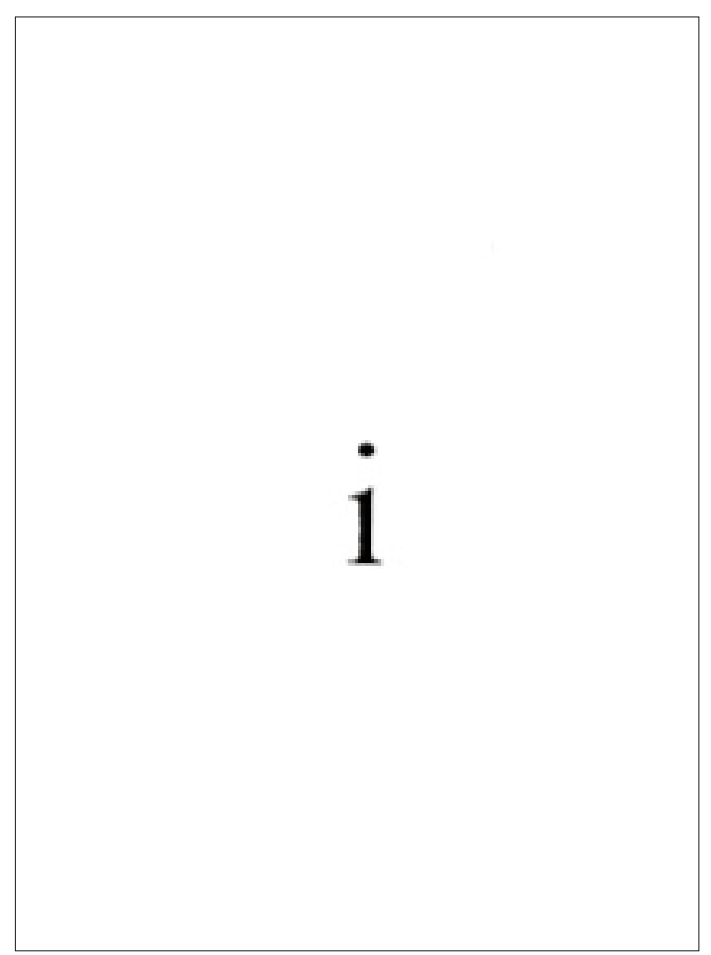

Fig. 6. José Luis Castillejo, The Book of I's, 1969. 240x160 mm, Constanza (Alemania), colección particular de la familia del artista. medio específico pictórico ${ }^{60}$, y que sí presentaba otros movimientos como el Minimal, un tipo de arte que Michael Fried interpretaría críticamente como literalista y teatral en su célebre ensayo Arte y objetualidad publicado en 1967.

Todos estos componentes puramente visuales en un medio como la pintura -que era al que se refería fundamentalmente Greenberg en sus teorías formalistas- le 1levaron, para diferenciarse del Minimal, al desarrollo de un concepto que se centraba en la experiencia artística propia del espectador. Un concepto cercano al componente de emoción puro-visualista que para Greenberg era imprescindible en un arte modernista de calidad: el efecto. Una experiencia emotiva experimentada por el espectador que se basaba en una vivencia de los elementos plásticos de valor artístico intrínsecos a la obra, contrarios a cualquier elemento externo narrativo o de tipo histórico. El efecto era un elemento de exposición inefable ${ }^{61}$, reservado únicamente al campo de la experiencia artística, y por tanto alejado de cualquier orden semántico cercano al lenguaje. Además, un arte de calidad para Greenberg destacaba los valores de unidad instantánea, ajenos a lo temporal, en la experiencia puro-visualista del espectador.

En medio de este debate se puede encuadrar The Book of I's, obra que había sido incluida por Lucy Lippard en su famosa crónica del arte experimental de la época, Seis años: La desmaterialización del objeto artístico de 1996 a 1972, junto a la obra de autores como Carl Andre, cercano al arte Minimal ${ }^{62}$. Esta colocación en la misma página del libro, quizás le llevó a Castillejo a concluir que la autora estaba relacionándole con etiquetas cercanas al Minimal, ya que en las conversaciones que mantuvimos en 2010, así como en una de las cartas que le envió a Greenberg en $1981^{63}$, el escritor mostraba su desacuerdo con la etiqueta minimalista que, según él, Lippard había otorgado a su The Book of I's. Lo cierto es que la norteamericana nunca etiquetó la obra de Castillejo de minimalista (fig. 6).

Siguiendo con este mismo debate, apreciamos que The Book of I's encierra un estudio en torno a los materiales que le son específicos al escritor relacionados con todo lo que compone el cuerpo del libro, algo que podría encajar dentro de los cánones del modernismo. Sin embargo, la renuncia a todo lo que tenía que ver con el estudio del signo y el símbolo (la semiótica) en Greenberg, que eran componentes básicos de la genealogía de Castillejo, nos llevan a determinar que esta conclusión de que The Book of I's fuera un libro modernista sería ampliamente rechazada por el crítico norteamericano. Además, Castillejo concibió un sistema de colocación de la letra 'i' en cada una de las páginas de esta obra que sí puede estar muy cerca de algunas composiciones minimalistas de Sol Lewitt, y que en ningún momento podría encajar dentro de los cánones de especificidad del medio puramente visual de la pintura donde, por otro lado, el concepto de emoción para Greenberg, como hemos visto, jugaba un papel fundamental. Una emoción propia de la experiencia artística que era inefable, que debía distanciarse del literalismo y la serialidad minimalistas y que no se cumple en la obra de Castillejo. El escritor

61 El concepto de effect (efecto), será argumentado por Greenberg en Complaints of an art critic (1967) donde también diferencia entre el subject (tema o argumento literario de una obra realista) y el contenido de la misma, del que dice es inexpresable mediante el lenguaje. GreEnBERG, 1993, pp. 269-272.

62 Lucy LipPARD, Seis años: La desmaterialización del objeto artístico de 1996 a 1972, Madrid, Akal, 2004, pp. 116.

63 Carta de José Luis Castillejo a Clement Greenberg del 24 de noviembre de 1981. 
ideó un sistema conectado con el lenguaje escrito, en este caso en inglés (de ahí el título que le dio al libro) en el que la letra "i” aparecía escrita en los números de páginas five, six, eight... quedando en blanco por ejemplo la primera página del libro cuyo número en inglés one no contiene la letra "i". Esta serie se continuaba hasta completar 400 páginas.

El libro, además, se distancia también del medio defendido por el modernismo de Greenberg, como es la pintura, por sus cualidades táctilo-temporales. A diferencia de la pintura, que se aprehende de una manera unitaria inmediata, una obra escrita en numerosas páginas como son las creaciones de Castillejo requiere de un tiempo y una manipulación física por parte del lector-espectador. Una experiencia que bien podría entrar en el terreno de lo performativo. La escritura es también un sistema cuyas formas están cerradas, dadas de antemano y por tanto alejadas de las formas únicas, arbitrarias, creadas por los artistas modernistas defendidos por Greenberg en el campo de la pintura. La escritura se aleja de los efectos de valores plásticos en los que estaba pensando el crítico norteamericano y entran en el campo de la semiótica. Elementos que pueden ser enunciados o pensados como fonemas, y que por tanto entrarían en el campo de lo sonoro distanciándose de una experiencia puro-visualista.

The Book of I's no fue un descubrimiento azaroso, sino

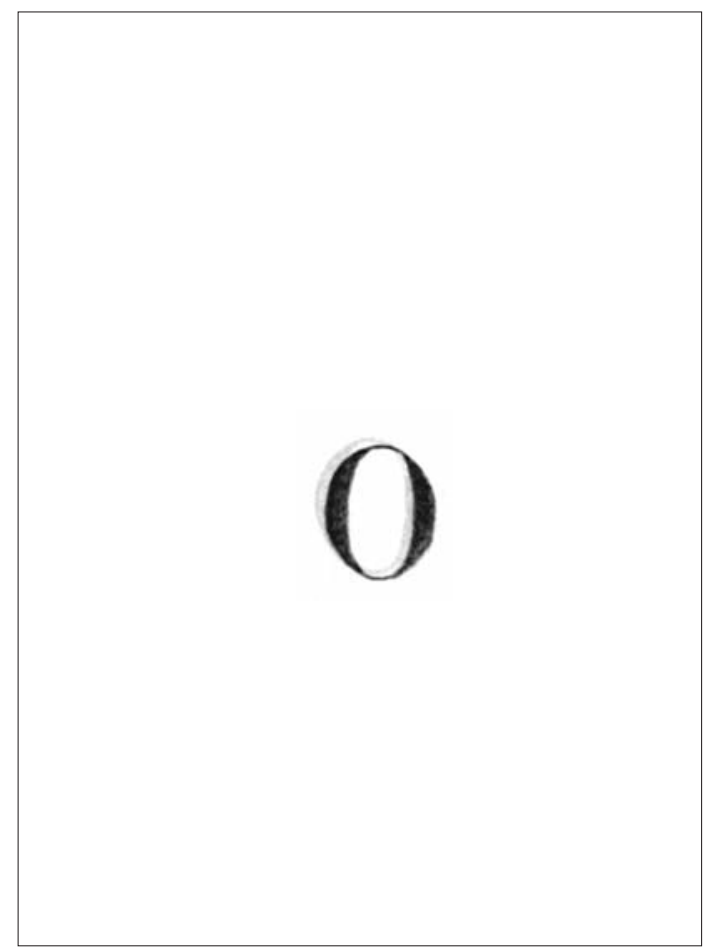

Fig. 7. José Luis Castillejo, El Libro de la $O$, circa 1968-1974. 270x215 mm, Bonn (Alemania), Colección particular. que su autor meditó cada uno de sus detalles durante varios meses tal y como dejó registrado en su manuscrito Diario de un Escritor y Notas de 1969 que el pintor y amigo de Castillejo, Carlos León, tuvo a bien mostrarme. Castillejo, así, reflexiona sobre la escritura constantemente sirviéndose de su unidad básica con el fin de potenciarla ${ }^{64}$. Con los medios que le son específicos a su campo de acción, experimenta y evoluciona, haciendo que el diseño o el dibujo no dominen a la obra. En este punto la teoría de Greenberg de la especificidad del medio tiene una correspondencia en el pensamiento de Castillejo. Sin embargo, la meditación conceptual en torno a los elementos semióticos del escritor se alejaría de nuevo del puro-visualismo pictórico defendido por el norteamericano.

En el Diario de un Escritor y Notas, Castillejo también describe un ejercicio de experimentación con la letra "O" mayúscula. Esta, que fue enormemente trabajada por Castillejo en un boceto de libro inédito titulado El Libro de la $O$, sin fechar, y que se encuentra en posesión de Carlos León, era parecido en su elaboración al sistema compositivo de The Book of I's (fig. 7). Castillejo pensaba ir situando distintas "O" juntas concéntricamente o por separado en cada página del libro en función de que la palabra que numeraba la página del libro empezara con la letra "O" o no. También si la palabra que numeraba la página contuviera una "O" pero ésta no fuera la primera letra de la palabra, por ejemplo, haría una "O" más pequeña. Este volumen fue realizado en Bonn durante su etapa como diplomático entre 1967 y 1974 y pertenece a su serie de obras de Los Libros Perversos ${ }^{65}$. Para su confección, Castillejo se ayudó de las plantillas tipográficas Letraset, que iba materializando en las hojas en blanco.

64 Idem, p. 109.

65 Acerca de la serie de Los Libros Perversos, realizo una aproximación de estudio en: Luis CÁcERES, "Los Libros Perversos. Una experiencia de transición en la escritura de José Luis Castillejo”, Voz y Letra, vol. XXVIII (2019), pp. 107-133. Los Libros Perversos, como el propio autor dejó de manifiesto, constaban de unos diez libros aproximadamente. Para la confección de mi artículo, gracias al pintor Carlos León, pude tener acceso a los que él conservaba. Estos son: El Libro de las Partículas, El Libro 
Como vemos, el parecido entre El Libro de la $O$ y The Book of I's es muy relevante. Según las propias palabras de Castillejo, realizó su serie de Los libros perversos (al que pertenece El Libro de la O) antes de realizar The Book of I's:

entre La Política y El Libro de las 18 Letras están mis Libros Perversos. Tuve una primera etapa de búsqueda, donde investigué creando una serie de libros, los llamados Libros Perversos, una serie de diez más o menos, los encuaderné y los fui regalando a amigos porque no me acabaron de convencer, no sé en qué manos estarán, recuerdo que a Carlos León le regalé alguno. Recuerdo que alguno de estos libros tenía unas enormes $\mathrm{O}$ en las páginas. Todos con la perversidad del surrealismo. En la siguiente etapa pasé un año preparando el futuro Libro de la I ${ }^{66}$.

Aquí Castillejo nos da algunas pistas de la confección de la serie de Los Libros Perversos. Y por supuesto nos surge la siguiente duda: ¿a qué se refiere Castillejo cuando habla de perversidad? Por un lado, Castillejo escribió en su Diario de 1969: "Hidalgo me liberó a medias porque me metió en la insensibilidad de la religión del vacío y la estética de la perversidad. Pero, en aquel momento, conocer a Hidalgo fue una liberación y mi gratitud continúa". Por otro lado, en varias citas del libro de Alfonso López Gradolí La Escritura Mirada. Una aproximación a la poesía experimental española, donde el autor le dedica una gran parte de su texto a Castillejo, aparecen también referencias al concepto de lo perverso. Las afirmaciones que revela Gradolí acerca de la obra de nuestro autor en su libro proceden de varias conversaciones que mantuvieron ambos en 1972:

El conjunto de la escritura - característica muy cuidada por JLC- ha de ser congruente, coherente, lógico. La unidad de ese conjunto no ha de romperse por una incongruencia perceptiva, es decir, por un elemento que se presente como arbitrariamente incorporado. Y la colocación del signo en el centro de una página ha de ser neutral. No ha de ser una colocación fetichista. El centro tiene la ventaja de centrar las cosas, mientras que el descentrarlas puede resultar perceptivamente injustificable, perverso o estético ${ }^{67}$.

La perversidad para el escritor, según esta cita, tiene que ver con un alejar la palabra o la letra del centro de la página, corriendo el peligro de caer en un culto esteticista y fetichista a la imagen gráfica, alejándose del mero ejercicio de escribir, el cual es, en principio, su práctica específica. En otra cita del libro de López Gradolí vuelve a aparecer el concepto de lo perverso:

Hoy en día la escritura se enfrenta con una servidumbre peor que la de la palabra hablada: el sometimiento a la imagen, a la dominación de nuestras vidas por las imágenes perversas, fetichistas, fascinantes de la publicidad y los llamados medios de comunicación. Con estas imágenes se mediatiza al público, incluso la política se está reduciendo a imagen. También al consumo, consumimos imágenes más que productos ${ }^{68}$.

Parece claro en estas citas que lo perverso para Castillejo se conecta con la llamada recepción del arte por las masas a través de los medios tecnológicos y con movimientos artísticos que caían en la idolatría de la imagen que el escritor rechazaba. Esto supone una metáfora también de la intromisión del esteticismo en la escritura.

A pesar de que El Libro de la $O$ sea considerado por Castillejo como perverso, es decir, que está cerca de un arte condenado por esteticista, lo cierto es que trabaja con la letra como elemento específico fundamental y elabora un sistema de colocación de la letra casi idéntico a The Book of I's. Ambas obras son muy similares, y sin embargo ¿por qué El Libro de la $O$ es un Libro Perverso mientras que The Book of I's es

de la O, El Libro de las Grandes Os y El Libro de la Cagada de la Mosca. Como vemos, si lo que recordaba Castillejo era correcto, aún quedan varios volúmenes de Los Libros Perversos por ser hallados y estudiados.

66 CAstillejo, 2013, p. 128.

67 Alfoso LóPez Gradolí, La Escritura Mirada. Una aproximación a la poesía experimental española, Madrid, Calambur, 2008, p. 209.

68 Ibidem, p. 210. 
una obra verdaderamente moderna o modernista? ¿Depende de que la letra escogida sea de un tipo u otro? ¿O depende de que esté reproducido en una imprenta o no? La respuesta está, en nuestra opinión, en que Los Libros Perversos (y El Libro de la $O$ es uno de ellos), son perversos porque para el autor están más cerca en su inspiración de otros medios y autores cercanos al Minimal o a la Poesía Concreta que al modernismo greenberguiano. Entonces, ¿por qué The Book of I's no es un libro perverso, si guarda tantas similitudes con El Libro de la $O$ ? ¿Es que quizás todos los libros post-Zaj de Castillejo como The Book of I's siguen guardando una conexión indudable con el arte neovanguardista, muy cercana a corrientes como el arte Minimal? Si nos ceñimos a algunas de las características de este movimiento como el anti-ilusionismo, el trabajo con materiales y elementos específicos, la aceptación de un medio como la escritura y el lenguaje (que no encajaría en el modernismo greenberguiano) encontramos grandes analogías con la obra post-Zaj de Castillejo como The Book of I's.

Las letras que usa Castillejo en sus libros, aunque puedan ser abstractas, como él mismo las denominó muchas veces al colocarlas en solitario en muchas de sus obras, siguen perteneciendo al código lingüístico, no pueden independizarse de su nivel semiótico y fonético. El modernismo greenberguiano no podría encajar este acoplamiento de su genealogía creada desde el análisis de la pintura en la práctica escrita. Esto no lo habría entendido Greenberg como una operación natural al formalismo puro-visualista del que provenía, sino que vería en la escritura de Castillejo un ejemplo de arte más bien conectado con los conceptualismos interesados por la semiótica y el lenguaje de los años 60 o una práctica concretista como deja aquí referenciado el propio escritor al hablar de su etapa post-Zaj:

Puede decirse que me quedé casi solo, sin ser comprendido, porque era muy difícil hacerlo por mis amigos los pintores, escultores y críticos modernos. Ellos, además, ya estaban amenazados primero por el vanguardismo radical y después por la reacción posmoderna. Es inútil decir que no pude lograr que se reconociera la posibilidad de una escritura moderna en medio de tanta escritura trivial que nada tenía de verdaderamente nueva, ya se llamase experimental, concreta, visual... Greenberg nunca entendió, ni menos aún comprendió, El libro de las íes (1969). Es decir, una escritura abstracta que no era mera poesía concreta ${ }^{69}$.

Castillejo, que como afirma Sandra Santana "no parece recurrir a ninguna teoría lingüística específi-

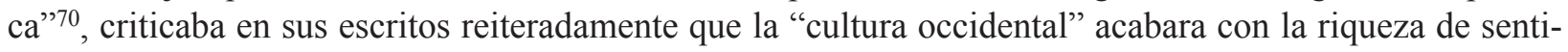
do del signo y del símbolo indistintamente:

El positivismo, laicismo y materialismo que han dominado la aún llamada cultura occidental -que en cuanto tal cultura no fue sino cristiana, mantenedora y renacentista de la civilización grecorromana de la que surge- han llevado en escritura al literalismo. Es decir, a la reducción del signo y el símbolo. No solo el signo quiere ser una descripción literal, sino también lo quiere ser el símbolo, como puede verse en tal actitud del racionalismo hacia lo simbólico ${ }^{71}$.

La escritura debía liberarse del sentido único y cerrado que la sociedad moderna había impuesto a las palabras según Castillejo. Esta era una intención compartida con la poesía concreta además de, desde nuestra opinión, el interés por la colocación de la letra o palabra en la página en blanco derivada de Mallarmé (Castillejo afirmaba su interés por Mallarmé) y la letra impresa. Sin embargo, Castillejo renunciaba a cualquier vinculación de su escritura con la música o lo sonoro o lo tecnológico que para los poetas concretos era esencial.

El escritor rechaza el componente fetichista de su escritura en cuanto a un fetichismo visual cercano al diseño y se basa en la máxima de acabar con el sentido literal del lenguaje, algo que desarrollará en su con-

\footnotetext{
69 Castillejo, 2006, p. 120.

70 Sandra Santana, “¿Cómo se lee una 'I'? Las imágenes de la escritura en la obra de José Luis Castillejo”, HIOL: Hispanic Issues Online, 21 (2018), p. 173.

71 Castillejo, 2006, p. 123; Fascina, 2000, p. 151.
} 
cepto de la "escritura no escrita". Una escritura que no evoca en el lector un sentido literal unívoco y cerrado, sino que siempre está abierto a diferentes concepciones. Un libro de un libro será la puesta en práctica de esta teoría que finalmente nunca llegó a materializarse en su forma final y que estaba basada en un libro de 400 páginas en blanco que deberían ser a su vez fotografiadas e impresas de distintas maneras. El fin último de esta acción era materializar una escritura simbólica de la luz, una escritura sin letras. Esta obra, a nuestro juicio, se acercaba más al campo de lo conceptual, y poco podía tener de modernista greenberguiano, en tanto en cuanto adolecía de cualquier ilusionismo puro-visualista.

\section{Conclusión}

La obra realizada por José Luis Castillejo tras su etapa en el colectivo Zaj no puede desvincularse precisamente de la genealogía fundacional que fue la razón de ser de su corpus práctico y teórico adquirido en los años en los que formó parte del grupo artístico español. Un análisis más hermenéutico de la correspondencia que mantuvieron el escritor y Greenberg a principios de los años 80 da muestras de un Castillejo afanado por recibir del crítico norteamericano la validez necesaria a sus planteamientos modernistas o de corte formalista de su trabajo. Sin embargo, como apuntamos en el texto, hay conceptos fundamentales defendidos por Greenberg que son inadaptables a la práctica escrita de Castillejo.

El interés por elementos que tienen que ver con el lenguaje y la semiótica vinculan la obra del escritor al surgimiento de las nuevas corrientes conceptualistas de los 60, interesadas en defender un arte al margen del puro-visualismo pictórico de corte formalista defendido por Greenberg tras la II Guerra Mundial. La práctica y el pensamiento de Castillejo, a pesar de que encuentra firmes analogías con el concepto de especificidad del medio o medium-specificity recogido por Greenberg (Castillejo en su obra post-Zaj no elabora performance u obras sonoras, sino que se ciñe fundamentalmente a la escritura), mantiene una gran divergencia con el estudio de los signos y los símbolos adscritos al lenguaje y claves en Castillejo, pero carentes de interés para la práctica modernista defendida por el crítico norteamericano.

La obra El Libro de la $O$ de la serie inédita de Los Libros Perversos en torno a la cual realizamos una aproximación en el artículo "Los Libros Perversos. Una experiencia de transición en la escritura de José Luis Castillejo" nos sirve para determinar ciertas evidencias que subrayan un debate crítico en torno al supuesto modernismo greenberguiano defendido por Castillejo en su obra posterior a Zaj. La puesta en relación de ese volumen con The Book of I's nos lleva a determinar que los libros realizados por el escritor tras su giro copernicano desde posiciones relacionadas con el arte de John Cage, el Minimal o la Poesía Concreta en Zaj, hacia posiciones más formalistas en solitario carecen de una base práctica objetiva y meramente analítica que la defina como tal.

LUIS CÁCERES CANTERO estudió Periodismo en la Universidad Antonio de Nebrija e Historia del Arte en la Universidad Complutense de Madrid. Máster por la Universidad Nacional de Educación a Distancia con especialidad en investigación acerca del arte de los años 60 en España y el grupo de arte conceptual ZAJ. Ha trabajado en diversos medios de comunicación como Wanadoo, Terra o ARNDigital escribiendo sobre arte, y ha creado proyectos editoriales como la revista TRAZOS especializada en la creación contemporánea. Actualmente trabaja como EducadorMediador en el Museo Nacional Centro de Arte Reina Sofía, actividad que combina con la docencia en la Universidad Antonio de Nebrija como profesor asociado donde imparte la asignatura Modern Art and Architecture in Spanish Cities. En la actualidad también cursa estudios de Doctorado por la Universidad Autónoma de Madrid donde investiga acerca de la obra del artista José Luis Castillejo.

Email:1cc271082@gmail.com

Código ORCID: https://orcid.org/0000-0003-2080-9379 